\title{
Possible Involvement of the Phloem Lectin in Long-Distance Viroid Movement
}

\author{
R. A. Owens, ${ }^{1}$ M. Blackburn, ${ }^{2}$ and B. Ding ${ }^{3}$ \\ ${ }^{1}$ Molecular Plant Pathology Laboratory, USDA-ARS, Beltsville, MD 20705, U.S.A.; ${ }^{2}$ Insect Biocontrol Labo- \\ ratory, USDA-ARS, Beltsville, MD 20705, U.S.A.; ${ }^{3}$ Department of Plant Biology and Plant Biotechnology \\ Center, Ohio State University, Columbus 43210, U.S.A. \\ Submitted 11 December 2000; Accepted 19 March 2001.
}

\begin{abstract}
Incubation with cucumber phloem exudate in vitro results in a dramatic decrease in the electrophoretic mobility of Hop stunt viroid. UV cross-linking and a combination of size exclusion and ion exchange chromatography indicate that this phenomenon reflects a previously unsuspected ability of phloem protein 2 , a dimeric lectin and the most abundant component of phloem exudate, to interact with RNA. In light of its demonstrated ability to move from cell to cell via plasmodesmata as well as long distances in the phloem, our results suggest that phloem protein 2 may facilitate the systemic movement of viroids and, possibly, other RNAs in vivo.
\end{abstract}

Additional keyword: RNA-binding protein.

To establish a systemic infection in a susceptible host, a plant viroid or virus must be able to leave the initially infected cell, move locally from cell to cell, and enter the phloem for long-distance transport. Viruses have evolved specialized movement proteins to exploit endogenous host RNA and protein transport systems (Carrington et al. 1996; Lazarowitz and Beachy 1999). Viroids, in contrast, are small, unencapsidated, circular RNAs that lack mRNA activity and are the smallest, autonomously replicating pathogens yet described (Flores et al. 1997; Owens 1999). Potato spindle tuber viroid (PSTVd) has been shown to move from source to sink in the phloem of infected tomato or Nicotiana benthamiana plants (Palukaitis 1987; Zhu et al. 2001). Trafficking is sustained by replication in phloem tissues and appears to be governed by plant developmental and cellular factors. Whether PSTVd (and other viroids) systemically move as free RNAs or ribonucleoprotein complexes is not known.

Phloem tissues of dicotyledonous plants contain several

Corresponding author: R. A. Owens; Telephone: +1-301-504-6209; Fax: +1-301-504-5449; E-mail: owensr@ba.ars.usda.gov

Disclaimer: Mention of a trademark or proprietary product does not constitute a guarantee or warranty of the product by the USDA and does not imply its approval to the exclusion of other products that also may be suitable.

This article is in the public domain and not copyrightable. It may be freely reprinted with customary crediting of the source. The American Phytopathological Society, 2001. proteinaceous structures (so called "P-proteins"), which are synthesized early in phloem ontogeny and are persistent into senescence (Thompson 1999). Phloem exudate from Cucurbita spp. contains a complex mixture of $>100$ proteins, including two abundant proteins: the phloem filament protein PP1, a 96-kDa protein that appears to be the primary structural protein involved in the formation of slime plugs that form at sieve plates following vascular disruption, and phloem lectin $\mathrm{PP} 2$, a $49-\mathrm{kDa}$ dimeric protein that preferentially binds $\mathrm{N}$ acetylglucosamine oligomers. PP1 and PP2 are moderately basic polypeptides. Unlike PP1, however, purified PP2 forms neither soluble polymers nor insoluble gels upon oxidation. In the Cucurbitaceae, PP2 is encoded by members of a small gene family (Bostwick et al. 1994).

Cucurbits provide a practical system for isolating $\mathrm{P}$ proteins and the genes that encode them. Studies by Thompson and colleagues (Balachandran et al. 1997; Bostwick et al. 1992; Dannenhoffer et al. 1997; Golecki et al. 1999; Leineweber et al. 2000) have shown that i) genes encoding PP2 are expressed developmentally in phloem companion cells; ii) a variety of phloem proteins, including PP2, are able to move from cell to cell through plasmodesmata; and iii) PP1 and PP2 move toward sink tissues within the assimilate stream. Mechanical inoculation of cucumber (Cucumis sativus L. cv. Suyo) with Hop stunt viroid (HSVd) results in systemic infection and the induction of a severe disease response (Shikata 1987). We screened phloem exudate collected from uninfected cucumbers for the presence of protein(s) that are able to bind HSVd such as putative viroid movement proteins. Evidence presented below shows that PP2 can interact with a variety of RNA molecules, specifically with highly structured viroid RNAs such as HSVd and polyadenylated mRNAs.

Aliquots of phloem exudate were collected from cut petioles of 6- to 8-week-old uninfected cucumber plants growing in the greenhouse and diluted immediately with 4 vol of extraction buffer (200 mM Tris-HCl, pH 8.2; 1 mM EDTA; 20 mM dithiothreitol; $1 \mathrm{mM}$ phenylmethylsulfonyl fluoride) to prevent oxidation and gel formation. Total protein concentration of the stabilized exudate was approximately 4 to $8 \mathrm{mg}$ per $\mathrm{ml}$, as determined by the Bradford assay (Bio-Rad, Hercules, CA, U.S.A.), with bovine serum albumin (BSA) as a standard. Subsequent electrophoretic mobility shift assays were carried out in the presence of either $0.2 \times$ Tris-borate-EDTA and $50 \mathrm{mM} \mathrm{NaCl}$ or $25 \mathrm{mM}$ Na phosphate (pH 7.0) and $25 \mathrm{mM} \mathrm{NaCl}$, essentially 
as described by Lane et al. (1992). In most assays, heparin was added to suppress potential nonspecific protein-RNA interactions $(200 \mu \mathrm{g}$ per ml) (Tanguay and Gallie 1996).

Data presented in Figure 1A illustrate the effect of unfractionated phloem exudate on the electrophoretic mobility of

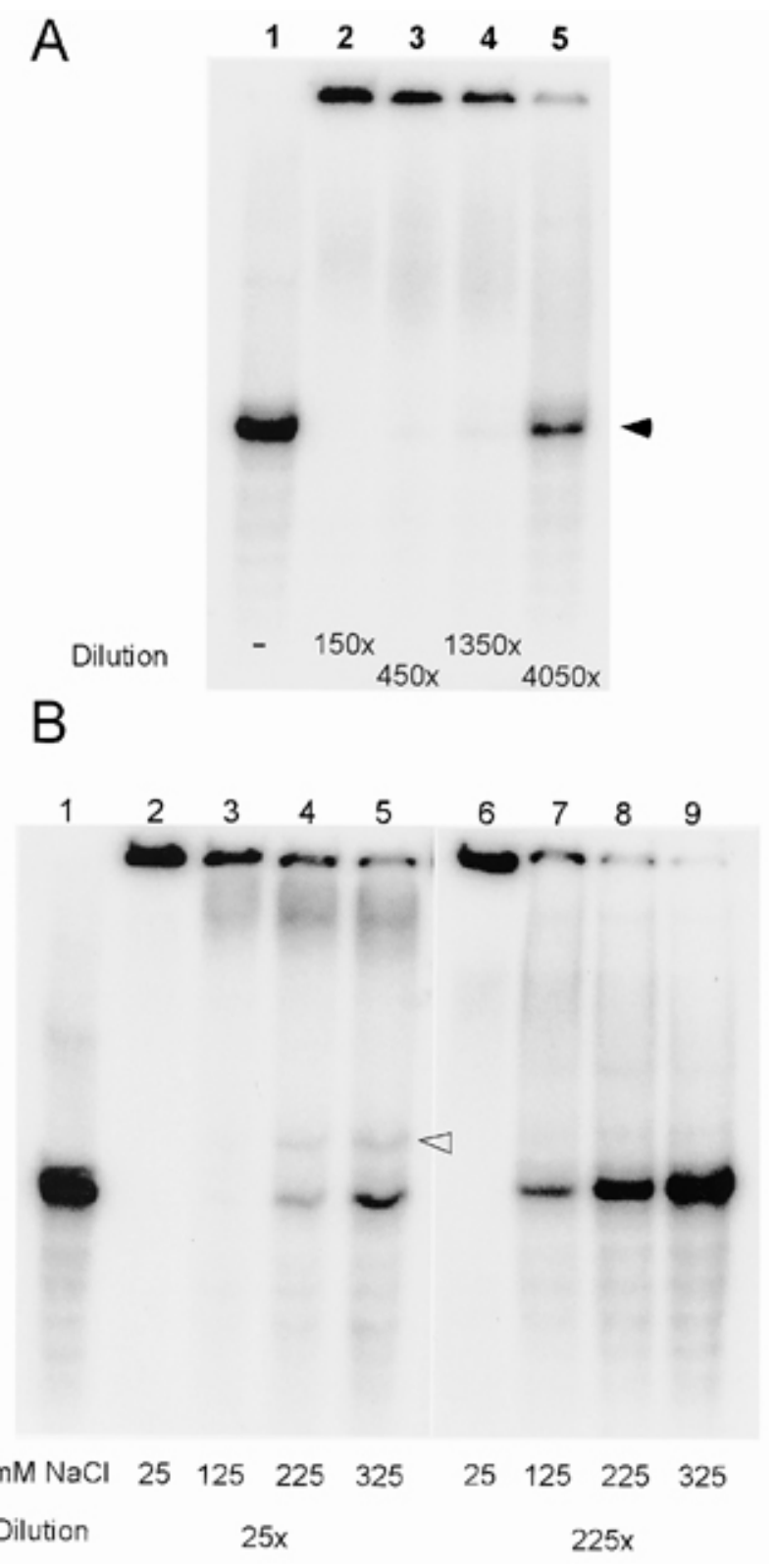

Fig. 1. Effect of protein concentration and ionic strength on the interaction of Hop stunt viroid (HSVd) with phloem protein(s). A, Serial threefold dilutions of unfractionated cucumber phloem exudate were incubated with $\left[{ }^{32} \mathrm{P}\right] \mathrm{HSVd}$ RNA transcripts for $30 \mathrm{~min}$ at $0^{\circ} \mathrm{C}$ in the presence of $25 \mathrm{mM}$ Na phosphate ( $\mathrm{pH} 7.0$ ), $25 \mathrm{mM} \mathrm{NaCl}$, and $5 \mathrm{mM}$ dithiothreitol before application to a $5 \%$ polyacrylamide gel containing $1 \times$ Trisborate-EDTA buffer and 5\% glycerol and electrophoresis at $15^{\circ} \mathrm{C}$. Solid arrow $=$ protein-free HSVd; dilution = relative concentration of phloem exudate in vivo compared with its concentration in the binding assay. B, Effect of ionic strength on formation of HSVd complexes. Binding assays were carried out as described above, except for the presence of additional $\mathrm{NaCl}$ in lanes 3-5 and 7-9. Note the appearance of a welldefined, rapidly migrating complex (open arrow) at higher ionic strength and exudate concentration. linear HSVd RNA transcripts. Comparison of lanes 1 through 4 shows that incubation with high concentrations of protein converted virtually all of the rapidly migrating $\left[{ }^{32} \mathrm{P}\right] \mathrm{HSVd}$ to large complexes that were unable to enter the gel matrix. The addition of smaller amounts of exudate resulted in the formation of a smear of smaller, slowly migrating complexes (barely visible in lanes 3 through 5) and the reappearance of protein-free HSVd. The addition of control proteins such as BSA had no effect on HSVd mobility (results not shown).

These initial experiments were carried out under low-salt conditions, approximately $50 \mathrm{mM} \mathrm{NaCl}$. Stability of the HSVd-containing complexes is dependent strongly upon protein concentration (Fig. 1B). Comparison of lanes 8 and 9 with lanes 4 and 5 revealed that a ninefold reduction in phloem exudate concentration (from 1/25 to $1 / 225$ of that present in vivo) virtually abolished complex formation at salt concentrations $\geq$ physiological levels (170 to $180 \mathrm{mM} \mathrm{NaCl}$ ). At the higher protein concentration, an increase in salt concentration led to the formation of more rapidly migrating complexes, including one migrating only slightly slower than protein-free HSVd (compare lanes 2 through 5).

Next, we used a combination of size exclusion and ion exchange chromatography to identify the protein(s) in phloem exudate that was able to interact with HSVd. Chromatography on Sephacryl S200 (Amersham Pharmacia Biotech, Piscataway, NJ, U.S.A.) removed virtually all higher molecular weight proteins from fractions containing PP2 (Fig. 2A and B, compare fractions 32 and 33 with 26 and 27). Also note that inclusion of $300 \mathrm{mM} \mathrm{NaCl}$ in the column buffer resulted in dissociation of the 49-kDa PP2 homodimer. After concentration, paired fractions were tested for their ability to interact with HSVd or polyadenylated coat protein mRNA transcripts of Potato virus $X$, and RNA binding activity cochromatographed with monomeric PP2 (Fig. 2C and D).

Although free of higher molecular weight proteins, Sephacryl S200 fractions 30 through 33 also contained several proteins smaller than PP2. One of these smaller proteins, CmPP16, was of particular interest because XoconostleCázares et al. (1999) showed that this viral movement protein paralog has a strong affinity for single-stranded RNA. Fortunately, differences in the theoretical pI values for PP2 and PP16 (9.65 versus 6.11) allow these two proteins to be separated by chromatography on a strong cation exchanger. When size-selected PP2 was applied to a Vydac 400VHP575 column (Separations Group, Hesperia, CA, U.S.A.) equilibrated with $10 \mathrm{mM}$ Na phosphate, $\mathrm{pH} 6.8$, and eluted with a 0 to $500 \mathrm{mM}$ $\mathrm{NaCl}$ gradient, the resulting profile exhibited two major peaks. Both peaks contained essentially pure PP2 and exhibited strong HSVd-binding activity (results not shown).

Additional evidence for the ability of cucumber PP2 to interact with RNA was obtained by a combination of UV crosslinking (Li and Palukaitis 1996; Wagenmakers et al. 1980) and Northwestern analysis. UV irradiation of unfractionated exudate in the absence of exogenous RNA resulted in the appearance of a band in the position expected for a PP2 dimer (Fig. $3 \mathrm{~A}$, compare lanes 2 and 4). Data presented in Figure 3B shows that irradiation in the presence of $\left[{ }^{32} \mathrm{P}\right] \mathrm{HSVd}$, followed by digestion with RNase $\mathrm{A}$, resulted in the transfer of ${ }^{32} \mathrm{P}$ to a species somewhat larger than a PP2 homodimer: 54,250 versus 48,950 $\mathrm{kDa}$. Unfortunately, polyclonal antisera against purified pumpkin PP2 reacts only weakly with PP2 from cu- 
cumber. When the experiment (Fig. 3A) was repeated with phloem exudate collected from pumpkin (Cucurbita maxima cv. Big Max), Western analysis revealed that the minor band that appears after UV irradiation does indeed contain PP2 (results not shown). Finally, immobilized molecules of PP2 that had been renatured after sodium dodecyl sulfatepolyacrylamide gel electrophoresis and transferred to a nitrocellulose membrane were also able to bind $\left[{ }^{32} \mathrm{P}\right] \mathrm{HSV}$ d RNA (Fig. 3C). Note the absence of binding to a smaller protein corresponding to CmPP16 (Fig. 3C, lanes 2 and 3); wheat germ extract (Fig. 3C, lane 4) has previously been shown to contain a number of RNA-binding proteins (Tanguay and Gallie 1996).

The ability of PP2 to interact with RNA molecules having very different structures, a small, highly structured RNA such as HSVd and a larger, less-structured viral mRNA containing polyA, raises questions about the specificity of this interaction as well as the nature and location of the RNA-binding site(s). Incubation with phloem exudate in the presence of $175 \mathrm{mM}$ $\mathrm{NaCl}$ results in the conversion of approximately $65 \%$ of the input $\left[{ }^{32} \mathrm{P}\right] \mathrm{HSVd}$ to slowly moving or immobile PP2-RNA complexes (Fig. 4, lanes 1 and 2). The addition of unlabeled competitor RNA (either HSVd or PSTVd) resulted in an in- crease of protein-free $\left[{ }^{32} \mathrm{P}\right] \mathrm{HSVd}$ RNA from approximately $35 \%$ (lane 2) to as much as 72 to $79 \%$ (lanes 4 through 6 and 8 through 10, respectively) of the input. Despite its inability to infect cucumber, PSTVd competed just as effectively as HSVd for binding to PP2. Also note that binding appears to be reversible in that the effect of adding unlabeled competitor was not time dependent (compare lanes 4 through 6 and 8 through 10). PSTVd was also able to compete effectively for binding to PP2 at a lower ionic strength $(25 \mathrm{mM} \mathrm{NaCl})$. Under these conditions, however, unlabeled PSTVd added $15 \mathrm{~min}$ after mixing the $\left[{ }^{32} \mathrm{P}\right] \mathrm{HSVd}$ and phloem exudate competed less effectively than the same amount of competitor added at $\mathrm{T}_{\mathrm{o}}$ (results not shown). Binding of RNA by PP2 in vitro appears to be nonsequence specific.

At the present time, evidence for the interaction of PP2 with RNA in vivo is indirect. Several studies (Kühn et al. 1997; Lucas et al. 1995; Ruiz-Medrano et al. 1999) have shown that, similar to viral RNAs, certain cellular mRNAs are able to move from cell to cell and circulate throughout the plant via the phloem. Among the proteins implicated in mRNA movement is CmPP16, a host paralog to viral movement proteins and a minor component of pumpkin phloem exudate (Xoconostle-Cázares et al. 1999). Although its ability to bind
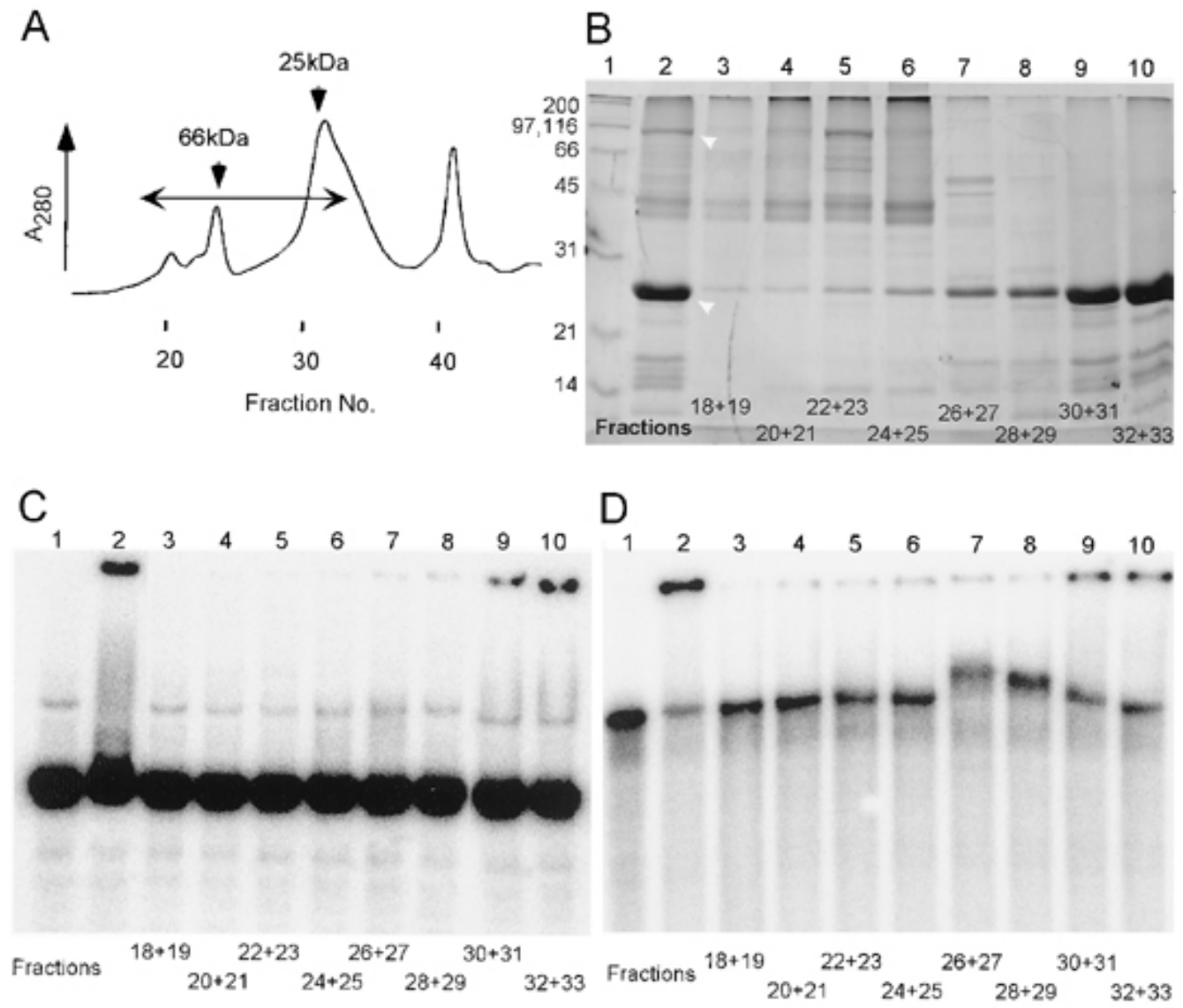

Fig. 2. Copurification of RNA-binding activity with cucumber PP2. Stabilized phloem exudate $(1.5 \mathrm{ml}, 11.25 \mathrm{mg}$ of total protein) was diluted with an equal volume of $50 \mathrm{mM}$ Na phosphate (pH 7.0), $300 \mathrm{mM} \mathrm{NaCl}$, and $5 \mathrm{mM}$ dithiothreitol and applied to a $2.6 \times 90 \mathrm{~cm}$ column of Sephacryl S200 (Amersham Pharmacia Biotech, Piscataway, NJ, U.S.A.) equilibrated with the same buffer and maintained at $4^{\circ} \mathrm{C}$. Ten-milliliter fractions were collected at a flow rate of $0.5 \mathrm{ml}$ per min and, after concentration (approximately tenfold), selected fractions were analyzed by B, sodium dodecyl sulfatepolyacrylamide gel electrophoresis analysis and tested for the ability to interact with C, Hop stunt viroid or D, a synthetic PVX coat protein mRNA. A, UV absorbance profile shows the positions of the bovine serum albumin $(66 \mathrm{kDa})$ and chymotrypsinogen A ( $25 \mathrm{kDa})$ standards used to calibrate the Sephacryl S200 column. B-D, Lane 2 contains unfractionated phloem exudate; B, positions of PP1 (96 kDa) and PP2 (24 kDa) are marked by arrows. 
RNA is strongly concentration dependent, PP2 is far more abundant than CmPP16. Similar to CmPP16, PP2 moves long distances in the phloem (Golecki et al. 1999). Unfortunately, HSVd does not replicate systemically in pumpkin (Shikata

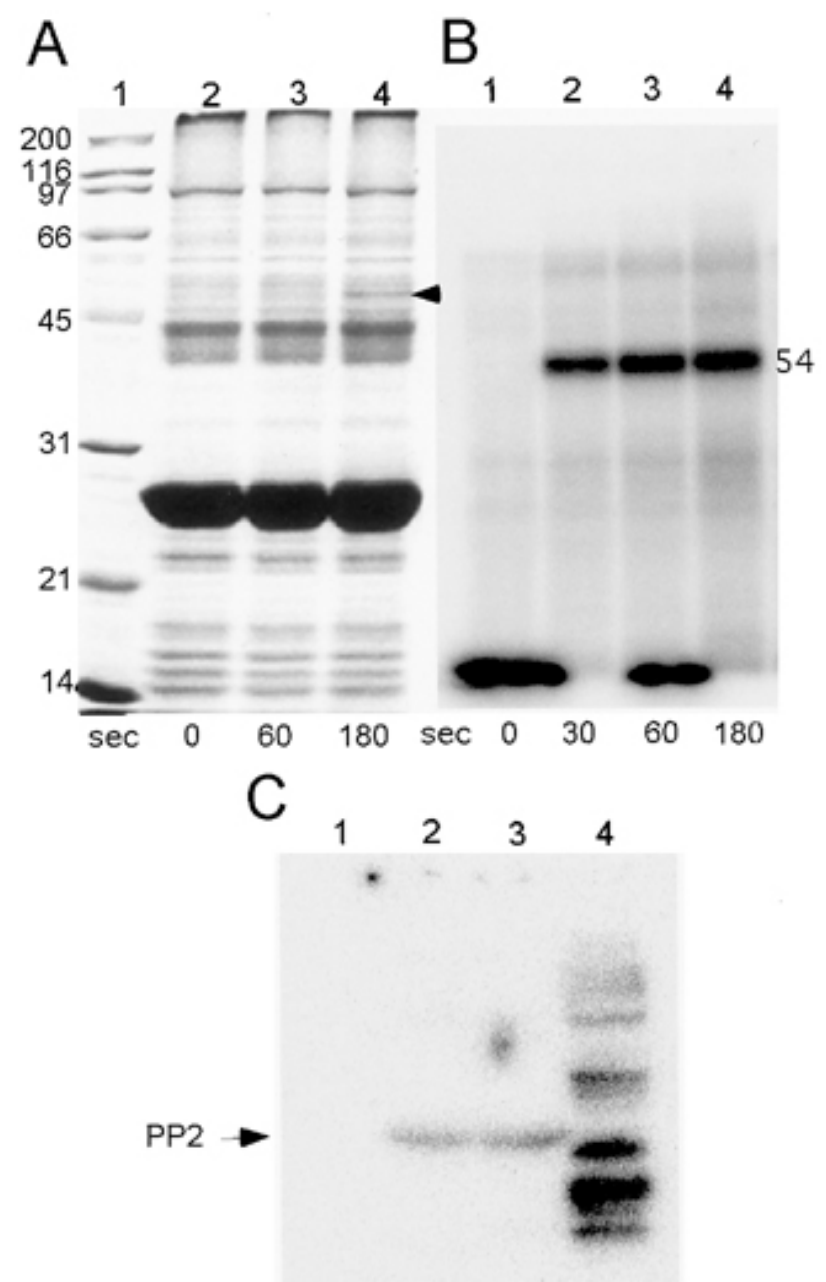

Fig. 3. UV-induced cross-linking of PP2 to Hop stunt viroid (HSVd) in vitro. A, Formation of a cross-linked PP2 homodimer in the absence of exogenous RNA. Lane 1: Sypro Orange standards (Bio-Rad, Hercules, CA, U.S.A.); lanes 2-4: unfractionated cucumber phloem exudate (approximately $5 \mu \mathrm{g}$ ) irradiated for 0,60 , or $180 \mathrm{~s}$ in the absence of exogenous RNA. Note the appearance of new protein species (arrow) migrating more slowly than the 45$\mathrm{kDa}$ ovalbumin standard after irradiation. B, Transfer of ${ }^{32} \mathrm{P}$ from HSVd RNA to a 50-55-kDa polypeptide following UV irradiation and RNase A digestion. Binding reactions $(10 \mu \mathrm{l})$ containing approximately $10 \mu \mathrm{g}$ of phloem protein were irradiated at $0^{\circ} \mathrm{C}$ in a UV Stratalinker 1800 (Stratagene, La Jolla, CA, U.S.A.), before the addition of $4 \mathrm{ng}$ of RNase A and incubation for $30 \mathrm{~min}$ at room temperature. After denaturation, samples were fractionated by $12 \%$ sodium dodecyl sulfate-polyacrylamide gel electrophoresis (SDS-PAGE) (Sambrook et al. 1989) and stained with SYPRO Orange (Molecular Probes, Eugene, OR, U.S.A.) before the gel was dried and resulting image was recorded with a phosphoimager (Bio-Rad). Lane 1: control (-UV); lanes 2-4: UV treated $(30,60$, or $180 \mathrm{~s}$, respectively). C, Interaction of HSVd with monomeric PP2. Following SDS-PAGE, samples containing either no protein (lane 1), cucumber phloem exudate (lanes 2-3), or wheat germ extract (Promega, Madison, WI, U.S.A) were transferred to an Optitran-supported nitrocellulose membrane (Schleicher \& Schuell, Einbeck, Germany), renatured as described (Sambrook et al. 1989), and incubated for $2.5 \mathrm{~h}$ at $0^{\circ} \mathrm{C}$ with $\left[{ }^{32} \mathrm{P}\right] \mathrm{HSVd}$ RNA in the presence of $20 \mathrm{mM}$ HEPES-KOH, $\mathrm{pH} 7.5 ; 25 \mathrm{mM}$ $\mathrm{NaCl}$; and $5 \mathrm{mM}$ dithiothreitol. After washing in the same buffer, the image of the damp membrane was recorded.
1987). As a result, it has not yet been possible to use immunoprecipitation followed by reverse transcription-polymerase chain reaction (Freire and Pagès 1995) to obtain direct evidence for the in vivo interaction of PP2 with HSVd.

PP2 is a basic protein with a theoretical pI value of 9.65 (8.59, if six cysteine residues are taken into account). Many plant RNA-binding proteins have modular structures similar to those of transcription factors, but comparison of PP2 with sequence profiles in the Conserved Domain Database (National Center for Biotechnology Information, Bethesda, MD, U.S.A.) failed to reveal any of the sequence motifs commonly found in RNA-binding proteins (Burd and Dreyfuss 1994; Mar Alba and Pagès 1998). Although deletion of its $\mathrm{N}$-terminus reduces the efficacy and extent of PP2 movement, neither the N-terminal 77 nor the C-terminal 40 amino acids are essential for interaction with plasmodesmata (Balachandran et al. 1997). Effects of these deletions on the RNA binding activity of PP2 are currently under investigation.

In the Cucurbitaceae, PP2 is encoded by members of a small gene family (Bostwick et al. 1994). BLAST searches (Altschul et al. 1997) with pumpkin PP2 as query sequence revealed convincing similarities with a variety of other plant lectins as well as two putative disease-resistance-related open reading frames (ORFs) from Arabidopsis (GenBank accession nos. AC004512 and BAB0940.1; results not shown). Similarities with the Arabidopsis ORFs involve neither the Tollinterleukin 1 receptor nor the nucleotide-binding site and leucine-rich repeat motifs present in the Nicotiana glutinosa $\mathrm{N}$ gene product and related resistance proteins (HammondKosack and Jones 1997). Chisholm et al. (2000) recently described the molecular characterization of $R T M 1$, a gene that controls the long-distance movement of Tobacco etch virus in Arabidopsis. RTM1 is a member of a large family of related proteins from the Brassicaceae that contain one or more copies of a jacalin (lectin)-like domain and have been implicated in defense against insects, fungi, and viruses. Clearly, an evolutionary perspective will be very important to understanding the role of PP2 in viroid-host interactions and normal plant growth and development.

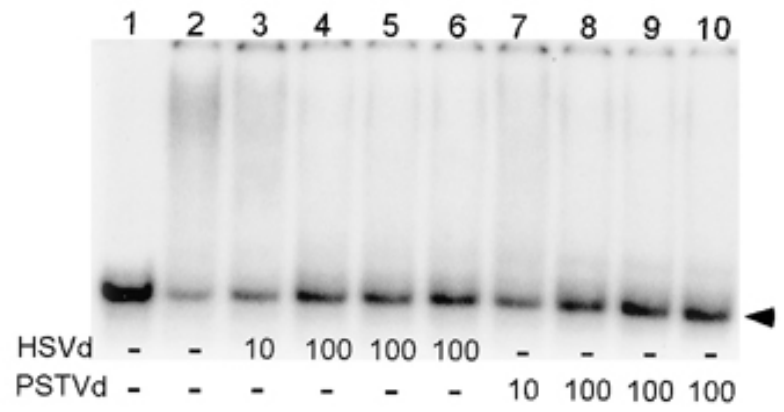

Fig. 4. Effect of unlabelled competitor RNAs on the interaction of Hop stunt viroid (HSVd) with cucumber PP2. Electrophoretic mobility shift assays $(10 \mu \mathrm{l})$ containing $16 \mathrm{ng}$ of $\left[{ }^{32} \mathrm{P}\right] \mathrm{HSVd}$ and $175 \mathrm{mM} \mathrm{NaCl}$ were carried out as described in Figure 1. Lanes 2-10: 25-fold diluted cucumber phloem exudate; lanes 3-10: tenfold or 100-fold excess of unlabelled competitor such as HSVd (lanes 3-6) or PSTVd (lanes 7-10) competitor RNA. Lanes 3-4 and 7-8: unlabelled competitor was added before the phloem exudate. Lanes 5-6 and 9-10: competitor was added either 10 (lanes 5 and 9) or 20 (lanes 6 and 10) $\mathrm{min}$ later. Arrow = protein-free HSVd. 


\section{ACKNOWLEDGMENTS}

We thank G. A. Thompson (University of Arkansas, Little Rock, U.S.A.) for continuing discussions, gifts of anti-pumpkin PP2 antisera and cloned PP2 cDNAs, and critical review of this manuscript. This work was supported partially by NRI grant 97-35303-4519 to B. Ding.

\section{LITERATURE CITED}

Altschul, S. F., Madden, T. L., Schäffer, A. A., Zhang, J., Zhang, Z., Miller, W., and Lipman, D. J. 1997. Gapped BLAST and PSI-BLAST: A new generation of protein database search programs. Nucleic Acids Res. 25:3389-3402.

Balachandran, S., Xiang, Y., Schobert, C., Thompson, G. A., and Lucas, W. J. 1997. Phloem sap proteins from Cucurbita maxima and Ricinus communis have the capacity to traffic cell to cell through plasmodesmata. Proc. Natl. Acad. Sci. USA 94:14150-14155.

Bostwick, D. E., Dannenhoffer, J. M., Skaggs, M. I., Lister, R. M., Larkins, B. A., and Thompson, G. A. 1992. Pumpkin phloem lectin genes are specifically expressed in comparison cells. Plant Cell 4:15391548.

Bostwick, D. E., Skaggs, M. I., and Thompson, G. A. 1994. Organization and characterization of Cucurbita phloem lectin genes. Plant Mol. Biol. 26:887-897.

Burd, C. G., and Dreyfuss, G. 1994. Conserved structures and diversity of functions of RNA-binding proteins. Science 265:615-621.

Carrington, J. C., Kasschau, K. D., Mahajan, S. K., and Schaad, M. C. 1996. Cell-to-cell and long-distance transport of viruses in plants. Plant Cell 8:1669-1681.

Chisholm, S. T., Mahajan, S. K., Whitham, S. A., Yamamoto, M. L., and Carrington, J. C. 2000. Cloning of the Arabidopsis RTM1 gene, which controls restriction of long-distance movement of tobacco etch virus. Proc. Natl. Acad. Sci. USA 97:489-494.

Dannenhoffer, J. M., Schulz, A., Skaggs, M. I., Bostwick, D. E., and Thompson, G. A. 1997. Expression of the phloem lectin is developmentally linked to vascular differentiation in cucurbits. Planta 201:405-414.

Flores, R., DiSerio, F., and Hernández, C. 1997. Viroids: The noncoding genomes. Semin. Virol. 8:65-73.

Freire, A., and Pagès, M. 1995. Functional characteristics of the maize RNA-binding protein MA16. Plant Mol. Biol. 29:797-807.

Golecki, B., Schulz, A., and Thompson, G. A. 1999. Translocation of structural P proteins in the phloem. Plant Cell 11:127-140.

Hammond-Kosack, K. E., and Jones, J. D. G. 1997. Plant disease resistance genes. Annu. Rev. Plant Physiol. Plant. Mol. Biol. 48:575-607.

Kühn, C., Franceschi, V. R., Schultz, A., Lemoine, R., and Frommer, W. B. 1997. Macromolecular trafficking indicated by localization and turnover of sucrose transporters in enucleate sieve elements. Science
275:1298-1300.

Lane, D., Prentki, P., and Chandler, M. 1992. Use of gel retardation to analyze protein-nucleic acid interactions. Microbiol. Rev. 56:509-528.

Lazarowitz, S. G., and Beachy, R. N. 1999. Viral movement proteins as probes for intracellular and intercellular trafficking in plants. Plant Cell 11:535-548.

Leineweber, K., Schulz, A., and Thompson, G. A. 2000. Dynamic transitions in the translocated phloem filament protein. Aust. J. Plant Physiol. 27:733-741.

Li, Q., and Palukaitis, P. 1996. Comparison of the nucleic acid- and NTP-binding properties of the movement protein of cucumber mosaic cucumovirus and tobacco mosaic tobamovirus. Virology 216:71-79.

Lucas, W. J., Bouché-Pillon, S., Jackson, D. P., Nguyen, L., Baker, L., Ding, B., and Hake, S. 1995. Selective trafficking of KNOTTED1 homeodomain protein and its mRNA through plasmodesmata. Science 270:1980-1983.

Mar Alba, M., and Pagès, M. 1998. Plant proteins containing RNArecognition motifs. Trends Plant Sci. 3:15-21.

Owens, R. A. 1999. Viroids. Pages 1928-1937 in: Encyclopedia of Virology, 2nd ed. A. Granoff and R. G. Webster, eds. Academic Press, New York.

Palukaitis, P. 1987. Potato spindle tuber viroid: Investigation of the long-distance, intra-plant transport route. Virology 158:239-241.

Ruiz-Medrano, R., Xoconostle-Cázares, B., and Lucas, W. J. 1999. Phloem long-distance transport of CmNACP mRNA: Implications for supracellular regulation in plants. Development 126:4405-4419.

Sambrook, J., Fritsch, E. F., and Maniatis, T. 1989. Molecular Cloning: A Laboratory Manual. Cold Spring Harbor Laboratory, Cold Spring Harbor, NY, U.S.A.

Shikata, E. 1987. Hop stunt. Pages 279-290 in: The Viroids. T. O. Diener, ed. Plenum Press, New York.

Tanguay, R. L., and Gallie, D. R. 1996. Isolation and characterization of the 102-kilodalton RNA-binding protein that binds to the $5^{\prime}$ and $3^{\prime}$ translational enhancers of tobacco mosaic virus RNA. J. Biol. Chem. 271:14316-14322.

Thompson, G. A. 1999. P-protein trafficking through plasmodesmata. Pages 296-313 in: Plasmodesmata: Structure, Function, Role in Cell Communication. A. J. E. van Bol and W. J. P. van Kesteren, eds. Springer Verlag, New York.

Wagenmakers, A. J. M., Reinders, R. J., and Van Venrooij, W. J. 1980. Cross-linking of mRNA to proteins by irradiation of intact cells with ultraviolet light. Eur. J. Biochem. 112:323-330.

Xoconostle-Cázares, B., Xiang, Y., Ruiz-Medrano, R., Wang, H.-L., Monzer, J., Yoo, B.-C., McFarland, K. C., Franceschi, V. R., and Lucas, W. J. 1999. Plant paralog to viral movement protein that potentiates transport of mRNA into the phloem. Science 283:94-98.

Zhu, Y., Green, L., Woo, Y.-M., Owens, R. A., and Ding, B. 2001. Cellular basis of potato spindle tuber viroid systemic movement. Virology 279:69-77. 